DOI 10. 18307/2015. 0622

(C) 2015 by Journal of Lake Sciences

\title{
冰封期达里诺尔湖同位素与营养盐分布特征及关系的定量分析“
}

刘晓旭 ${ }^{1,2}$, 李畅游 ${ }^{1 * *}$, 李文宝 ${ }^{1}$, 赵胜男 ${ }^{1}$, 甄志磊 ${ }^{1}$, 刘志娇 ${ }^{1}$, 于瑞雪 ${ }^{1}$

( 1 : 内蒙古农业大学水利与土木建筑工程学院, 呼和浩特 010018)

(2: 内蒙古水务投资 (集团) 有限公司, 呼和浩特 010020$)$

摘 要: 以内蒙古高原的达里诺尔湖为研究对象, 对其在冰封期湖水不同相态下总氮 ( TN)、总磷 (TP) 浓度以及氢、氧同 位素比值的分布特征和定量关系进行初步研究. 结果表明:1) 在冰封期, 达里诺尔湖水体中营养盐的平均浓度相对较高, 已远超过国家 $\mathrm{V}$ 类水质标准. 水体中 $\mathrm{TN}$ 、 $\mathrm{TP}$ 浓度均大于其在对应冰体中的浓度, 均值分别是对应冰体中的 9.91、3.11 倍, 说明低温冷冻过程对达里诺尔湖水体中的氮、磷具有浓缩效应. 而通过与非冰封期的对比发现, 湖冰的排氮效应强于 磷. 2) 冰封期由于结冰过程中同位素热力学分馏明显, 加之贡格尔河的人流补给, 使得达里诺尔湖冰体中的氢、氧同位素 比值远高于水体中的比值, 同时, 随冰层的加深, 同位素逐渐偏重. 3) 冰封期达里诺尔湖水体及冰体中, 同位素比值与营 养盐浓度均呈显著负相关, 水体的相关性较冰体要好, 在冰层中, 随着冰层的加深相关性越明显. 利用 SPSS 统计软件分析 发现同位素比值与营养盐浓度的相关关系显著, 水体中最大相关系数达到 0.991 , 冰体中达到 0.988 ; 氢同位素 (D) 与 $\mathrm{TN} 、 \mathrm{TP}$ 浓度的关系式分别为: TN $=-0.2825 \delta \mathrm{D}-6.0083$ 和 $\mathrm{TP}=-0.0805 \delta \mathrm{D}-1.2395$, 这为研究湖泊营养盐的时空变化 规律提供新的手段和理论.

关键词: 氢、氧同位素;氮; 磷; 冰封期;相关关系;达里诺尔湖

\section{The distribution and relationship of isotope and nutrient during freeze-up period in the Lake Dalinuoer: A quantitative approach}

\author{
LIU Xiaoxu ${ }^{1,2}$, LI Changyou ${ }^{1}$, LI Wenbao ${ }^{1}$, ZHAO Shengnan ${ }^{1}$, ZHEN Zhilei $^{1}$, LIU Zhijiao ${ }^{1} \&$ YU Ruixue \\ ( 1 : College of Water Conservancy and Civil Engineering, Inner Mongolia Agricultural University, Hohhot 010018, P. R. China) \\ (2: Inner Mongolia Water Industry Investment (GHroup) Limited Company, Hohhot 010020, P. R. China)
}

Abstract: This study aims at understanding the distribution characteristic and the correlativity of total nitrogen ( TN), total phos-
phorus ( TP), hydrogen isotope ( D ) and oxygen isotope $\left({ }^{18} \mathrm{O}\right)$ in ice layer and water during the freeze-up period in Lake Dalinuoer
of Inner Mongolia. The results show that: 1 ) The Lake Dalinuoer water with high content of nutrient is even worse than the fifth lev-
el of water quality ( Chinese standard) during freeze-up period. The concentrations of TN and TP in water are higher than those of
in ice layer above the water during the freeze-up period. They are 9.91 times and 3.11 times in water higher than those of the ice
layer, respectively. It is caused by the process of concentration effect on nitrogen and phosphorus when the lake water freezes up.
It can be found that the interception content of nitrogen is relatively higher than phosphorus in the ice layer, comparing with the un-
frozen period. 2 ) The effect of thermodynamic isotope fractionation and the inflow supplies of Gongger River together make that iso-
tope content in ice much larger in water during freeze-up period. The isotope content is increasing from the top ice to the bottom
one. 3 ) The content of isotopic and nutrient appeares significantly negative correlation during the freeze-up period. The correlation
relationship in water is stronger than that in ice, and bottom ice stronger than the top one. It was found that the closest correlation
coefficients is 0.991 in lake water, and 0.988 in ice, calculated by SPSS software. The quantitative relationship between the con-
tent of isotope and nutrient (eg. the relationship function: TN = - $0.2825 \delta \mathrm{D}-6.0083$ and TP = - $0.0805 \delta \mathrm{D}-1.2395$ ) will

* 国家自然科学基金重点项目 (51339002)、国家自然科学基金项目 (51469025)、内蒙古自治区重大科技项目 (20091408)、内蒙古自然科学基金项目(2012MS0615) 和西部地区博士后人才资助计划项目 (2014M562495XB) 联 合资助. 2014-09-26 收稿;2015-03-09 收修改稿. 刘晓旭 (1991 ), 女, 硕士研究生; E-mail: 15848130960@ 163. com.

** 通信作者;E-mail:nndlichangyou@163.com. 
provide a new method for studying temporal and spatial variation of nutrient content in the lake.

Keywords: Hydrogen and oxygen isotope; nitrogen; phosphorus; freeze-up period; correlation relationship ; Lake Dalinuoer

中国寒旱区的湖泊, 不仅是历史气候变迁的重要指示器和环境变化研究的切入点, 而且是寒旱区水循 环的重要环节和不可缺失的构成部分. 加之气候和环境等因素, 北方的寒旱区湖泊具有明显的地域特性. 认 识和研究寒旱区湖泊, 不仅是服务国计民生的急需, 而且是丰富湖泊学科内容、拓宽学科领域之必需 ${ }^{[1]}$. 近 年来, 人类活动推动了流域氮、磷营养盐输移的快速发展, 使浮游藻类异常繁殖, 很多淡水湖泊由草型湖 泊快速转变为藻型湖泊, 湖泊生态平衡遭到破坏. 因此, 研究氮、磷营养盐对改善湖泊生态具有重要的意 $义^{[2]}$. 目前为止, 对水体氮 $(N)$ 、磷 $(P)$ 、碳 $(C)$ 、有机物等研究都是在非冰冻条件下进行的, 如东湖、巢湖、 太湖等湖泊水体富营养化及有机物污染的研究 ${ }^{[3-5]}$, 而冰封期湖泊研究也仅集中在湖泊水位与面积变化 的气候因素分析上 ${ }^{[6]}$, 进一步对冰封条件下冰体一水体间营养盐的分布特征及相互关系的研究则更加少 见 $^{[7]}$. 随着对稳定同位素分馏效应认识的深人以及同位素分析技术的发展, 氢、氧同位素作为理想的天然 示踪剂能有效应用于湖泊研究中. 目前, 湖泊氢、氧稳定同位素的研究多集中在讨论补给关系 ${ }^{[8-10]}$ 及同位 素质量平衡的应用上 ${ }^{[11-13]}$. 湖泊中同位素分馏效应有较多体现 ${ }^{[14-16]}$, 而湖泊结冰过程中的分馏效应却涉 及的很少. 虽然, 已有研究利用碳、氮稳定同位素技术指示出外源输人对生态系统影响的可行性 ${ }^{[17-20]}$, 建 立湖水盐度与同位素的定量关系式 ${ }^{[21]}$, 并探究夏季同位素与各离子的相关关系 ${ }^{[22-23]}$, 但是对冰封期湖泊 同位素水一冰分布特征以及与营养盐浓度变化之间相互关系、湖泊水一冰中营养盐浓度分布特点的研究却 很少.

达里诺尔湖 (简称达里湖), 位于内蒙古自治区赤峰市克什克腾旗境内. 本文以内蒙古达里湖为研究对 象, 通过研究湖泊冰封期总氮 $(\mathrm{TN})$ 、总磷 $(\mathrm{TP})$ 以及氢同位素 $(\mathrm{D})$ 、氧同位素 $\left({ }^{18} \mathrm{O}\right)$ 在冰层和水体中的分布特 征, 并对冰封期的 TN TP 浓度与 $\delta \mathrm{D} 、 \delta^{18} \mathrm{O}$ 的关系进行相关分析. 将首次通过湖泊冰封期 $\delta \mathrm{D} 、 \delta^{18} \mathrm{O}$ 的分布特 征指示湖泊水一冰中营养盐的分布特点, 这将为今后研究湖泊冰封期营养盐分布的变化规律提供基础理论 依据.

\section{1 材料与方法}

\section{1 研究区概况}

达里湖 $\left(43^{\circ} 12^{\prime} \sim 43^{\circ} 24^{\prime} \mathrm{N}, 116^{\circ} 24^{\prime} \sim 116^{\circ} 56^{\prime} \mathrm{E}\right)$ 位于内蒙古自治区赤峰市克什克腾旗西部, 南临浩瀚的 浑善达克沙地, 是我国北方典型的旱寒区湖泊之一. 受季风性气候影响, 降水主要集中在夏季 $6-8$ 月, 多年 平均降雨量为 $400 \sim 500 \mathrm{~mm}$, 蒸发量为 $1500 \sim 1600 \mathrm{~mm}$. 现有水域面积约 $190 \mathrm{~km}^{2}$, 且湖水由西向东逐渐变 浅, 从约 $12 \mathrm{~m}$ 逐渐减少为 $1 \sim 2 \mathrm{~m}$. 湖水偏碱性, 年平均 $\mathrm{pH}$ 值为 8.52 , 部分河段有时高达 $9.82^{[24]}$. 在矿化程 度方面, 其水体中主要含有 $\mathrm{Na}^{+}$与 $\mathrm{K}^{+}$等. 受湖水 $\mathrm{pH}$ 值等因素影响, 湖泊中鱼类种群简单, 主要有瓦氏雅罗 鱼 (Leuciscus waleckii) 和鲫鱼 (Carassius auratus). 克什克腾旗境内的贡格尔河、亮子河、沙里河、浩来河 4 条 河流流人达里湖,河流水量小,泥沙少,达里湖的水系构成比较简单,便于开展各项科学研究.

\section{2 样品的采集}

根据达里湖的面积、水深及人湖河口位置的分布特征, 结合研究目的, 本文采用全球定位系统定位, 在湖区布设 10 个采样点 (图 1), 并于 2012 年 12 月在冰冻的湖面上破冰钻孔采集冰样和冰下水样, 测量 湖水深和冰的厚度. 采集冰样时, 在破冰的过程中尽量保持冰块完整, 收集 $15 、 35 、 65 \mathrm{~cm}$ 处的冰块到样品 瓶中, 采样前样品瓶均事先用原水反复润洗多次. 用深水采样器采集冰面下和湖底处水样, 并立即用封口 膜密封在 $500 \mathrm{ml}$ 的聚乙烯瓶中, 避免因蒸发而引起同位素分馏. 同位素样品在测定之前经 $0.45 \mu \mathrm{m}$ 的滤 膜过滤.

\section{3 样品的分析方法}

稳定氢、氧同位素比值 $\delta \mathrm{D} 、 \delta^{18} \mathrm{O}$ 采用美国 LGR 公司 LMIA-V2 (DLT-100) 液态水同位素分析仪测定 ( DZ/T 0184.19-1997), 精确度 $(1 \sigma):{ }^{18} \mathrm{O} /{ }^{16} \mathrm{O}$ 优于 $0.1 \%, \mathrm{D} / \mathrm{H}$ 优于 $0.3 \%$. 总氮 ( TN)、总磷 $(\mathrm{TP})$ 浓度分别 用碱性过硫酸钾和钼酸铵消解后, 用 U-2001 紫外可见分光光度计测定 (GB 11894-1989 $)^{[25]}$. 


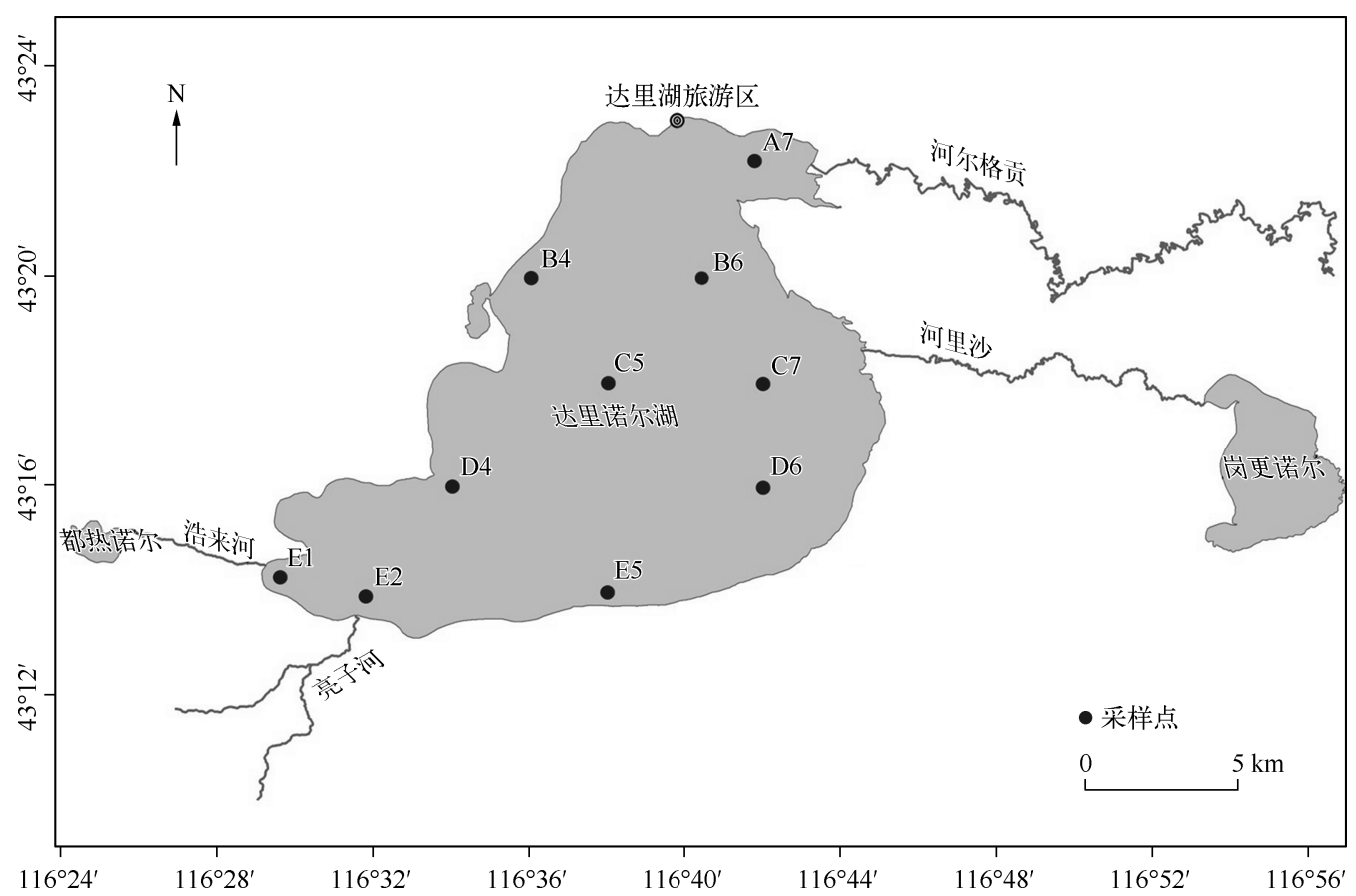

图 1 达里湖采样点位置

Fig. 1 The location of water sampling sites in Lake Dalinuoer

\section{2 结果}

\section{1 营养盐在不同相态水中浓度的分布}

$\mathrm{N} 、 \mathrm{P}$ 的形态、浓度、空间分布及季节性变化规律主要受湖泊水体输人和其转化过程的影响, 因此湖泊水 体内 N、P 形态和浓度存在着有迹可循的时空变化特征 ${ }^{[26-27]}$. 通过对水体及不同冰层冰体中的营养盐浓度 (冰体中营养盐浓度取 3 个冰层的平均值) 进行测定, 发现 TN 或 TP 浓度在达里湖水的 2 种相态中变化规律 相似, 并且 2 种营养盐在冰中的浓度明显低于对应其在水中的浓度, TN 浓度在冰体一水体 2 相中的差异尤 为明显 (图 2). 在水的同一相态角度观察, TN 和 TP 浓度的空间变化趋势基本一致, 其浓度出现的极值点也 一致.

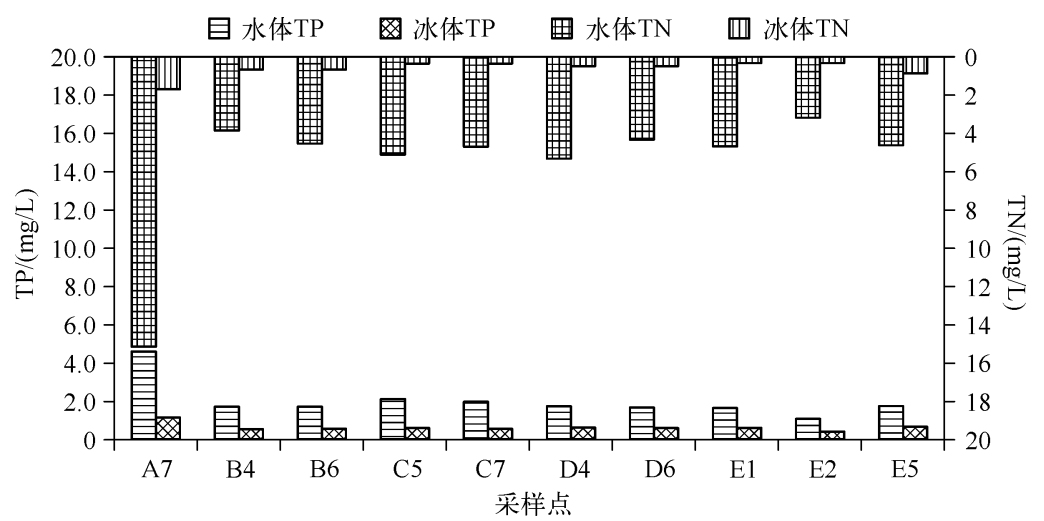

图 2 达里湖内营养盐在水的不同相态中的浓度对比

Fig. 2 The comparison of nutrient concentrations within ice and water in Lake Dalinuoer 
在水体中, $\mathrm{TN}$ 浓度范围为 $3.14 \sim 15.14 \mathrm{mg} / \mathrm{L}$, 各点浓度均值为 $5.51 \mathrm{mg} / \mathrm{L}$; TP 浓度范围为 $1.10 \sim$ $4.66 \mathrm{mg} / \mathrm{L}$, 各点浓度均值为 $2.02 \mathrm{mg} / \mathrm{L}$. 在冰体中, $\mathrm{TN}$ 浓度范围为 $0.25 \sim 1.69 \mathrm{mg} / \mathrm{L}$, 各点浓度均值为 0.57 $\mathrm{mg} / \mathrm{L}$; TP 浓度范围为 $0.45 \sim 1.15 \mathrm{mg} / \mathrm{L}$, 各点浓度均值为 $0.65 \mathrm{mg} / \mathrm{L}$. 在冰体与水体中, 位于达里湖北部的 A7 点 TN $、$ P 浓度均最高, 与其他点相差较大.

\section{2 同位素在不同相态水中比值的分布}

由蒸发、凝聚、降落和径流等过程所形成的水体, 因形成条件不同而具有不同的同位素特征 ${ }^{[28]}$. 通过对 达里湖不同冰层和水体中的 $\delta \mathrm{D} 、 \delta^{18} \mathrm{O}$ 进行测定 (图 3) 发现, $\delta \mathrm{D}$ 或 $\delta^{18} \mathrm{O}$ 在水的 2 种相态中变化规律相似, 并 且 2 种同位素在水体中的比值明显低于对应其在冰体中的比值. 在湖水的同一相态角度观察, $\delta \mathrm{D}$ 和 $\delta^{18} \mathrm{O}$ 的 空间变化趋势也基本一致,其比值出现的极值点也一致.

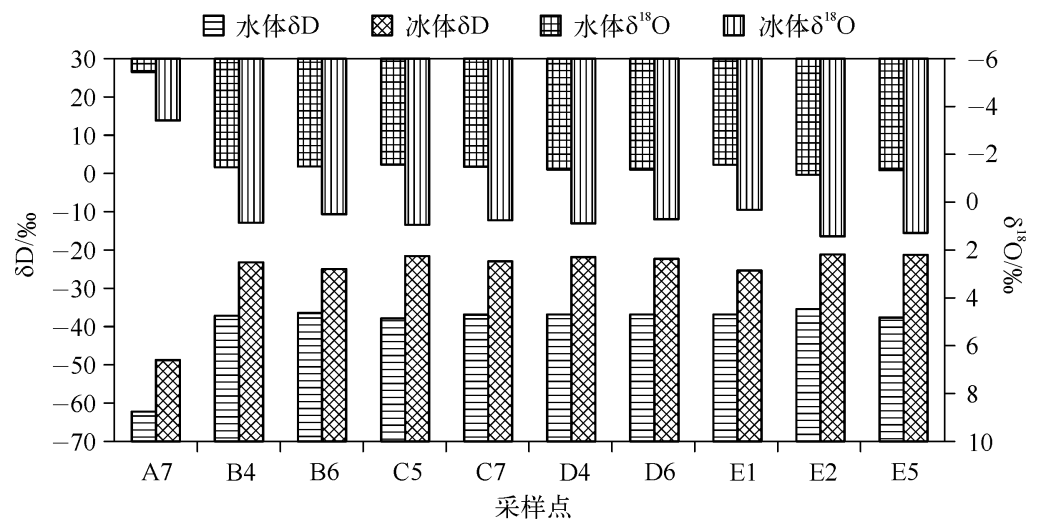

图 3 达里湖内同位素在水的不同相态中的比值对比

Fig. 3 The comparison of isotope content within ice and water in Lake Dalinuoer

在水体中, $\delta \mathrm{D}$ 变化范围为 $-62.19 \% \sim-34.99 \%$, 各点均值为 $-39.04 \% \%_{0} ; \delta^{18} \mathrm{O}$ 变化范围为 $-5.52 \% 0 \sim$ $-1.21 \%$, 各点均值为 $-1.89 \%$. 在冰体中, $\delta \mathrm{D}$ 变化范围为 $-48.49 \% 0 \sim-20.90 \%$, 各点均值为 $-24.98 \% 0$; $\delta^{18} \mathrm{O}$ 变化范围为 $-3.50 \% 0 \sim 1.35 \%$, 各点均值为 $0.36 \%$. 位于达里湖北部的 $\mathrm{A} 7$ 点的 $\delta \mathrm{D} 、 \delta^{18} \mathrm{O}$ 均最小, 且与 其他点相差较大, 这一规律与营养盐恰好相反.

\section{3 讨论}

\section{1 水体与冰体中营养盐浓度与同位素比值的分布特征}

达里湖湖泊水体中, TN 与 TP 浓度的空间分布规律基本相同, $\delta \mathrm{D}$ 与 $\delta^{18} \mathrm{O}$ 的空间分布规律也一致,而营 养盐浓度与同位素比值之间呈现相反的分布规律. 位于达里湖北部的 A7 点, 营养盐浓度与同位素比值相对 其他点均出现明显差异 (图 2, 图 3). A7 点 TN、TP 浓度分别为其余采样点的 3.14、2.69 倍, $\delta \mathrm{D} 、 \delta^{18} \mathrm{O}$ 分别比 其余点小 1.71 、 5.43 倍. $\mathrm{A} 7$ 点靠近北岸旅游景区, 受人为因素影响比较大, 污染较重; 此处生长有很多水草, 冬季水草死亡腐烂释放 $\mathrm{N} 、 \mathrm{P}^{[29]}$, 冰封期过低的水温直接影响到微生物的降解作用, 加之表面有冰层的覆盖, 使自然曝气形成的复氧过程几乎完全停止, 溶解氧浓度处于最低值; 该点冰厚 $0.92 \mathrm{~m}$, 水深只有 $2.08 \mathrm{~m}$ (表 1), 与湖区其他区域相比, 冰厚相差不大而水深较浅, 该点湖水的冷冻浓缩效应较大. 因此 A7 点营养盐 浓度明显高于其他点. 同时, 通过水样同位素测试发现 A7 点的 $\delta \mathrm{D}$ 和 $\delta^{18} \mathrm{O}$ 非常低, 此处为达里湖的淡水补 给河流——贡格尔河的人湖口, 该河流对达里湖的补给量占河流补给总量的 $75 \%$, 较低的贡格尔河水同位 素比值是 A7 点同位素比值较其他采样点小的主要原因 (河水进人湖泊后长期蒸发浓缩, 湖水 $\delta \mathrm{D} 、 \delta^{18} \mathrm{O}$ 会明 显高于河水).

达里湖冰体中营养盐浓度及同位素比值的变化规律不仅与水体中的变化规律相似, 而且出现的极值点 也吻合, 这说明结冰时水体并没有受到太大的扰动. 
表 1 达里湖各采样点冰厚及水深

Tab. 1 The depth of water and the thickness of ice at each sampling site in Lake Dalinuoer

\begin{tabular}{lcccccccc}
\hline & $\mathrm{A} 7$ 点 & $\mathrm{B} 4$ 点 & $\mathrm{C} 5$ 点 & $\mathrm{C} 7$ 点 & D6 点 & E1 点 & E2 点 & E5 点 \\
\hline 冰厚 $/ \mathrm{m}$ & 0.92 & 1.01 & 0.93 & 1.01 & 1.21 & 0.90 & 1.06 & 1.10 \\
水深 $/ \mathrm{m}$ & 2.08 & 5.79 & 7.57 & 6.29 & 5.79 & 7.20 & 8.44 & 6.70 \\
\hline
\end{tabular}

营养盐在水体和冰体中的浓度表现出明显差异 (图 4). 水体中 TN 、TP 浓度均值分别为 $5.51 、 2.02 \mathrm{mg} / \mathrm{L}$, 冰体中 TN、TP 浓度均值分别为 $0.57 、 0.65 \mathrm{mg} / \mathrm{L}$, 水体中 TN、TP 浓度均大于其在对应冰体中的浓度, 分别是 其对应冰体中的 9.91、3.11 倍. 这表明营养盐浓度水体高于冰体, 湖水中的营养盐在结冰过程中由冰体向水 体迁移 ${ }^{[30]}$. 结晶学理论认为, 在过冷过程中, 水体表层温度聚冷, 使该层的营养盐溶解度降低, 随着温度下 降, 部分营养盐快速析出, 增大形成临界尺寸冰核的可能性, 促使水体异相成核并加快冰层的形成 ${ }^{[31-33]}$. 水 分子浓度远低于整个液相中的水分子浓度, 营养盐的分子浓度则远高于整个液相中的营养盐分子浓度. 在 浓度差的推动下, 液相中的水分子向固液界面处扩散, 固液界面处的营养盐分子向液相扩散 ${ }^{[34]}$. 张岩等 ${ }^{[35]}$ 运用固一液相平衡理论、结晶学理论和热力学理论对呼伦湖冰封期污染特性进行过分析, 本研究发现, 这种 低温冷冻过程对水体污染物的浓缩效应在达里湖也有明显体现. 通过与呼伦湖的对比发现, 呼伦湖水体中 的 TN 、TP 浓度均值分别是其对应冰体中的 3.14 、2.20 倍, 而达里湖水体与冰体的 TN、TP 浓度差值远大于呼 伦湖, 表明春季达里湖比呼伦湖更容易暴发藻类水华. 此外, 达里湖的 TN 浓度最高为 $15.14 \mathrm{mg} / \mathrm{L}$, TP 浓度 最高为 $4.66 \mathrm{mg} / \mathrm{L}$, 已经远超过国家 V 类水标准 ${ }^{[36]}$, 达里湖的水生态治理亟待关注.

$\mathrm{TN}$ 在水体中的浓度是其对应冰体中的 9.91 倍, 比 TP 浓度水体-冰体倍数高 3 倍. 表现为结冰过程中, 冰体对 $\mathrm{N}$ 的影响要高于 P. 为证明此现象, 对非冰封期的 TN 、 TP 浓度进行测定, 发现达里湖冰封期水体中的 $\mathrm{TN}$ 浓度要大于非冰封期,而 TP 浓度基本与夏季保持一致,说明结冰过程中,湖水的排 $\mathrm{N}$ 效应强于 $\mathrm{P}$.

相似的, 达里湖同位素比值在冰体一水体中也呈显著差异 (图 4). 水体中各点 $\delta \mathrm{D}$ 的平均值为 $-39.03 \% 0, \delta^{18} \mathrm{O}$ 的平均值为 $-1.89 \%$; 冰体中各点 $\delta \mathrm{D}$ 的平均值为 $-24.98 \% 0, \delta^{18} \mathrm{O}$ 的平均值为 $0.36 \%$. 水体 中 $\delta \mathrm{D} 、 \delta^{18} \mathrm{O}$ 均小于其在冰体中的比值, 这一现象恰好与营养盐冰体一水体中的浓度特征相反. 对 15 、35、 $65 \mathrm{~cm}$ 不同厚度冰层的同位素比值进行分析, 表明 3 层冰体中的 $\delta \mathrm{D}$ 平均值分别为 $-26.20 \%$ 、 $-24.60 \%$ 、 $-24.13 \% 0, \delta^{18} \mathrm{O}$ 平均值分别为 $0.13 \%$ 、 $0.37 \%$ 、 $0.59 \%$. 其中, $\mathrm{A} 7$ 点的 $\delta \mathrm{D}$ 垂向分布分别为 $-50.22 \%$ 、 $-47.72 \%$ 、 $-47.53 \% 0, \delta^{18} \mathrm{O}$ 分别为 $-3.84 \%$ 、 $-3.42 \%$ 、 $-3.23 \%$. 由于 A7 点同位素比值的特殊性, 剔除 A7 点, 各点冰层中垂向 $\delta \mathrm{D}$ 平均值分别为 $-23.53 \%$ 、 $-22.03 \% 0-21.53 \%, \delta^{18} \mathrm{O}$ 平均值分别为 $0.57 \%$ 、 $0.79 \%$ 、 $1.01 \%$. 分析显示, 随着冰层深度的增加同位素逐渐偏重. 进人冬季, 由于湖水表面的热量损失, 当 湖水温度下降至结冰点时, 进一步冷却会导致湖水过冷却形成冰晶并形成薄冰层. 随着固体冰盖表面热量 交换, 在冰盖空隙中的水, 将会从水表面向下结冰, 这种热力生长将会超过冰盖的起始厚度而继续向下发 展 ${ }^{[37]}$. 这个过程中的同位素热力学分馏, 导致较轻的同位素不断运移到冰下水体中, 中重同位素富集在冰 中, 随着冰的生长, 冰层加厚, 同位素分馏继续, 越深层冰中富集的同位素越重. 其中, 分馏系数的大小与结 冰速度、冰体结构以及平衡点有关. 进一步, 在冰封期, 贡格尔河仍以小流量流人达里湖, 为湖泊水体带人了 较轻的同位素. 同时, 在冬季存在着直接来自湖面的微弱蒸发, 也对冰体一水体中同位素比值有一定影响. 这 些作用使得冰封期冰体中的同位素比值高于水体,且在冰层中随着冰厚加大,富集的同位素越重.

\section{2 同位素比值与营养盐浓度的相关性分析}

对达里湖水体和冰体的测定结果分析发现, 水体和冰体中营养盐浓度和同位素比值在湖泊不同位置都 有显著差异, 且同一位置同位素比值与营养盐浓度呈显著负相关. 由于受到河水输入的影响, A7 点冰体和 水体中的 $\delta \mathrm{D} 、 \delta^{18} \mathrm{O}$ 较其余采样点明显偏负, 其余采样点之间 $\delta \mathrm{D} 、 \delta^{18} \mathrm{O}$ 变化范围都比较小. 因此, 剔除 $\mathrm{A} 7$ 点 对营养盐浓度与同位素比值的相关关系进行分析 (表 2).

对冰封期达里湖的水体及冰体的同位素比值与营养盐浓度用 SPSS 统计软件做相关分析和显著性分 析, 发现在冰体中, 同位素比值与营养盐浓度呈一定的负相关关系, 且随着冰层加深相关性增强. 在 $65 \mathrm{~cm}$ 的 冰层中相关系数达到 0.988 , 剔除 A7 点后达到 0.769 . 在水体中, 同位素比值与营养盐浓度的相关性较冰体 

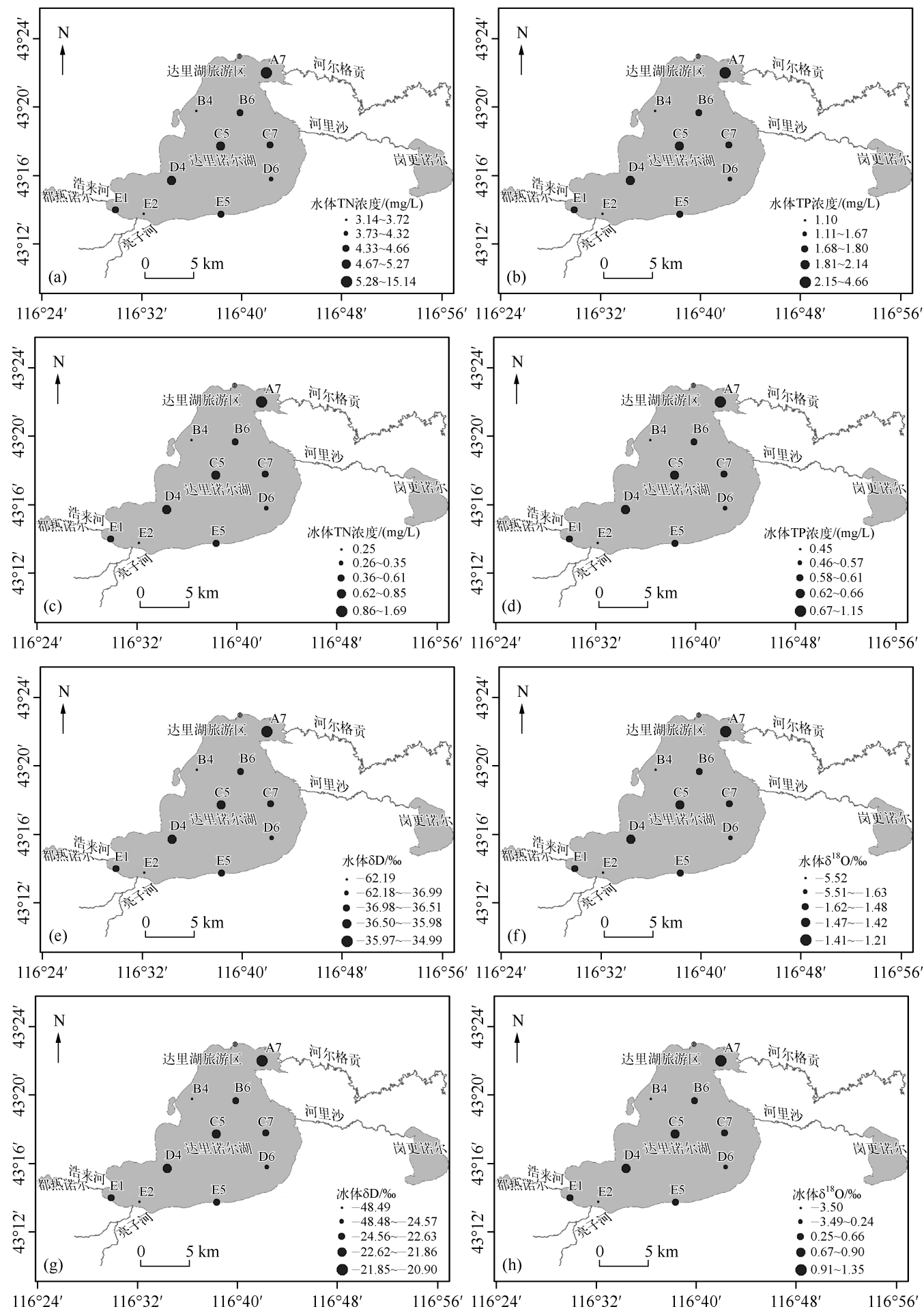

图 4 达里湖水体与冰体中营养盐浓度及同位素比值分布示意

Fig. 4 The distribution characteristics of nutrient concentrations and isotope content within water and ice in Lake Dalinuoer 
更好,均在 0.01 水平 (双侧检验) 上显著相关,相 关系数均达到 0.97 以上, 剔除 $\mathrm{A} 7$ 点后, 相关系 数基本达到 0.7 以上. 对水体与冰体的数据共同 作相关分析发现, 营养盐浓度与同位素比值呈显 著负相关, 相关系数均达到 0.8 以上, 剔除 A7 点 后相关系数均达到 0.9 以上. 通过比较发现 $\delta \mathrm{D}$ 与营养盐浓度的相关关系比 $\delta^{18} \mathrm{O}$ 要好, 可以得到 $\delta \mathrm{D}$ 与 $\mathrm{TN} 、 \mathrm{TP}$ 浓度的关系分别为 $\mathrm{TN}=-0.2825$ $\delta \mathrm{D}-6.0083$ 和 $\mathrm{TP}=-0.0805 \delta \mathrm{D}-1.2395$.

已有研究发现,夏季内蒙古河套平原湖泊的 氢、氧同位素组成与离子浓度、矿化度等水化学 指标存在显著相关性 ${ }^{[22]}$, 由于夏季湖泊蒸发过程 中存在明显的同位素分馏 ${ }^{\left[{ }^{38]}\right.}$, 相应的离子浓度也 浓缩增大,使得水体水化学指标与同位素比值呈 正相关关系. 在塔吉克斯坦湖泊水体中也发现了 相似的相关性 ${ }^{[23]}$. 冰封期的达里湖, 由于冰体的 冷冻浓缩效应导致冰下水体中营养盐浓度升高， 同时,结冰过程的同位素热力学分馏使得中重同 位素富集在冰中. 因此,在湖水静止且分布均匀 条件下,结冰厚度越大的区域,冰下水体中的同 位素比值越负, 营养盐浓度越大, 冰下水体的氢、 氧同位素比值与营养盐浓度存在负相关关系, 且 相较冰体来说相关性更好. 在冰生长过程中, 由 于同位素分馏作用,随着冰厚增加同位素越来越 富集, 由于冰生长速率与能量梯度作用下营养盐 在冰体内部迁移, 导致营养盐随冰厚增加浓度越

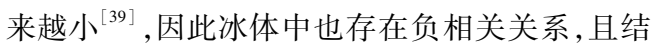
冰厚度越深相关关系越明显. 利用同位素比值与 营养盐浓度在冰一水以及冰体中的反相关关系，
表 2 冰封期达里湖 $\delta \mathrm{D} 、 \delta^{18} \mathrm{O}$ 与 $\mathrm{TN}$ 、 $\mathrm{TP}$ 浓度的相关性分析

Tab. 2 The correlation analysis between $\delta \mathrm{D}, \delta^{18} \mathrm{O}$ and TN, TP concentrations during the freeze-up period in Lake Dalinuoer

\begin{tabular}{|c|c|c|c|c|c|}
\hline \multirow{2}{*}{\multicolumn{2}{|c|}{ 水相 }} & \multicolumn{2}{|c|}{ 指标 } & \multirow{2}{*}{ 相关系数 } & \multirow{2}{*}{$\begin{array}{c}\text { 相关系数 } \\
\text { (剔除 A7 点) }\end{array}$} \\
\hline & & $\begin{array}{l}x / \\
\% 0\end{array}$ & $\begin{array}{c}y / \\
(\mathrm{mg} / \mathrm{L})\end{array}$ & & \\
\hline \multirow{4}{*}{\multicolumn{2}{|c|}{ 水体 }} & $\delta \mathrm{D}$ & $\mathrm{TN}$ & $-0.989^{* *}$ & -0.568 \\
\hline & & & $\mathrm{TP}$ & $-0.977^{* *}$ & $-0.866^{* *}$ \\
\hline & & $\delta^{18} \mathrm{O}$ & $\mathrm{TN}$ & $-0.991^{* *}$ & $-0.710^{*}$ \\
\hline & & & $\mathrm{TP}$ & $-0.978^{* *}$ & $-0.809^{* *}$ \\
\hline \multirow[t]{12}{*}{ 冰体 } & $15 \mathrm{~cm}$ & $\delta \mathrm{D}$ & $\mathrm{TN}$ & -0.181 & -0.398 \\
\hline & & & $\mathrm{TP}$ & $-0.640^{*}$ & -0.325 \\
\hline & & $\delta^{18} \mathrm{O}$ & $\mathrm{TN}$ & -0.083 & -0.114 \\
\hline & & & $\mathrm{TP}$ & -0.591 & -0.325 \\
\hline & $35 \mathrm{~cm}$ & $\delta \mathrm{D}$ & $\mathrm{TN}$ & -0.571 & -0.558 \\
\hline & & & $\mathrm{TP}$ & $-0.783^{* *}$ & -0.446 \\
\hline & & $\delta^{18} \mathrm{O}$ & $\mathrm{TN}$ & -0.585 & -0.315 \\
\hline & & & $\mathrm{TP}$ & $-0.787^{* *}$ & -0.422 \\
\hline & $65 \mathrm{~cm}$ & $\delta \mathrm{D}$ & $\mathrm{TN}$ & $-0.988^{* *}$ & -0.370 \\
\hline & & & $\mathrm{TP}$ & $-0.976^{* *}$ & -0.421 \\
\hline & & $\delta^{18} \mathrm{O}$ & $\mathrm{TN}$ & $-0.949^{* *}$ & $-0.769^{* *}$ \\
\hline & & & $\mathrm{TP}$ & $-0.961^{* *}$ & $-0.642 *$ \\
\hline \multirow{4}{*}{\multicolumn{2}{|c|}{ 水体及冰体 }} & $\delta \mathrm{D}$ & $\mathrm{TN}$ & $-0.876^{* *}$ & $-0.969^{* *}$ \\
\hline & & & $\mathrm{TP}$ & $-0.892^{* *}$ & $-0.953^{* *}$ \\
\hline & & $\delta^{18} \mathrm{O}$ & $\mathrm{TN}$ & $-0.865^{* *}$ & $-0.962 * *$ \\
\hline & & & $\mathrm{TP}$ & $-0.883^{* *}$ & $-0.948^{* *}$ \\
\hline
\end{tabular}

$*$ 表示在 0.05 水平 $($ 双侧 $)$ 上显著相关, $* *$ 表示在 0.01 水 平 (双侧) 上显著相关.

不仅可以尝试以环境同位素来指示 $\mathrm{N} 、 \mathrm{P}$ 的变化趋势及分布情况, 同时拓展了氢、氧同位素比值作为水体示 踪剂的用途 ${ }^{[40]}$, 对预测水质变化、进行水质评价及达里湖的生态治理具有重要意义.

\section{4 结论}

通过对达里湖内营养盐浓度和氢、氧同位素比值在水的不同相态中的变化规律进行研究, 利用统计学 方法, 得到冰封期达里湖水的不同相态中营养盐浓度和氢、氧同位素比值的变化特征以及它们之间的定量 关系, 具体结论如下:

1) 冰封条件下, 达里湖水体中 TN、TP 浓度均值分别为 $5.51 、 2.02 \mathrm{mg} / \mathrm{L}$, 分别是其对应冰体中 $\mathrm{TN}(0.57 \mathrm{mg} / \mathrm{L})$ 和 $\mathrm{TP}(0.65 \mathrm{mg} / \mathrm{L})$ 浓度均值的 $9.91 、 3.11$ 倍, 湖水中污染物在结冰过程中由冰体向水体迁 移, 表明低温冷冻过程对达里湖水体中的 N、P 有浓缩效应. 通过与非冰封期对比分析可知, 达里湖冰封期水 体中的 $\mathrm{N}$ 浓度要大于非冰封期, 而 $\mathrm{P}$ 浓度基本与夏季保持一致, 说明结冰过程中, 冰体的排 $\mathrm{N}$ 效应强于 $\mathrm{P}$.

2) 在与呼伦湖的对比后发现, 达里湖营养盐的平均浓度远高于呼伦湖, 且湖内营养盐浓度已远超过国 家 $\mathrm{V}$ 类水质标准. 贡格尔河的人湖口处受人为影响严重, 加之工业污水与生活废水的排人造成污染, 严重影 响整个湖泊的水质. 达里湖地区的水环境不应只靠夏季湖水的自净能力,水生态治理呆待解决.

3 ) 冰封条件下, 达里湖冰体中 $\delta \mathrm{D} 、 \delta^{18} \mathrm{O}$ 均值分别为 $-24.98 \% 、 0.36 \%$, 高于其在水体中的对应均值 (分 
别为 $-39.03 \%$ 和 $-1.89 \%$ ), 结冰过程中的同位素热力学分馏导致中重同位素富集在冰中, 同时, 贡格尔河 的人流补给和冬季冰面微弱的蒸发影响使得达里湖冰体中的同位素比值高于水体.

4) 在冰封期, 由于冰体冷冻浓缩效应与同位素热力学分馏效应, 使得湖水同位素比值与营养盐浓度呈 现明显的负相关关系; 在冰生长速率与能量梯度导致营养盐在冰体内部迁移的共同作用下伴随同位素分馏 效应, 使得冰体中存在负相关关系, 且随着冰层加深, 相关关系越显著. 水体中的相关关系较冰体更好, 冰体 中相关系数最大达到 0.988 , 水体中达到 0.991 , 冰体与水体相关关系均达 0.8 以上. 得到 $\delta \mathrm{D}$ 与 TN TP 浓度 的关系, 分别为 $\mathrm{TN}=-0.2825 \delta \mathrm{D}-6.0083$ 和 $\mathrm{TP}=-0.0805 \delta \mathrm{D}-1.2395$. 利用这个关系, 同位素示踪剂可 以成为一种证明和预测营养盐在冰一水、冰体中变化趋势的评价手段, 对水质监测和评价都具有重要的应用 价值.

致谢: 感谢达里诺尔国家级自然保护区生态旅游有限公司在采样过程中给予的大力帮助.

\section{5 参考文献}

[ 1 ] 胡汝瀷,姜逢清,王亚俊等. 论中国干旱区湖泊研究的重要意义. 干旱区研究,2007,24(2):137-140.

[2] 吴丰昌, 金相灿, 张润宇等. 论有机氮磷在湖泊水环境中的作用和重要性. 湖泊科学, 2010, 22 (1): 1-7. DOI 10. $18307 / 2010.0101$.

[ 3 ] 甘义群,郭永龙. 武汉东湖富营养化现状分析及治理对策. 长江流域资源与环境, 2004,13(3):277-281.

[ 4 ] 张 萝. 基于藻类增长生物学评价试验的巢湖水华预警研究 [学位论文]. 淮南: 安徽理工大学,2013:6.

[5] 成 刚. 太湖氮营养盐的分布特征及区域差异性研究 [学位论文]. 兰州: 兰州大学,2010.

[ 6 ] 丁永建, 刘时银, 叶柏生等. 近 50a 中国寒区与旱区湖泊变化的气候因素分析. 冰川冻土,2006,28 (5):623-632.

[ 7 ] 彭祥捷. 中国北方湖泊营养盐的迁移转化及富营养化风险分析一一长春南湖为例 [学位论文]. 长春: 吉林大学, $2011: 12$.

[ 8 ] 陈建生, 季㢶宸, 刘 震等. 内蒙古高原岱海接受远程深循环地下水补给的环境同位素及水化学证据. 湖泊科学, 2013,25 (4) :521-530. DOI 10. 18307/2013.0409.

[9] 张华安, 王乃昂, 李卓仑等. 巴丹吉林沙漠东南部湖泊和地下水的氢氧同位素特征. 中国沙漠, 2011, 31 (6): 1623-1629.

[10] 黄一民. 洞庭湖流域水循环中稳定同位素的变化特征及其影响机制研究 [学位论文]. 长沙: 湖南师范大学, $2013: 12$.

[11] 刘忠方, 田立德, 姚檀栋等. 基于 $\delta^{18} \mathrm{O}$ 的青藏高原中部错那湖湖水蒸发研究. 自然资源学报, 2009, 24 (11): 2014-2023.

[12] 巩同梁,田立德, 刘东年. 羊卓雍湖流域湖水稳定同位素循环过程研究. 冰川冻土,2007,29(6): 914-920.

[13] 高 晶, 田立德, 刘勇勤等. 青藏高原南部羊卓雍错流域稳定同位素水文循环研究. 科学通报, 2009, 54 (15): 2153-2159.

[14] 包为民,胡海英, 王 涛等. 蒸发血中水面蒸发氢氧同位素分馏的实验研究. 水科学进展, 2008,19(6):780-785.

[15] 藏娅琳. 羊卓雍错流域水体氢氧稳定同位素时空变化特征研究[学位论文]. 重庆:西南大学,2014:5.

[16] 王 杰,王文科,田 华等.环境同位素在三水转化研究中的应用.工程勘察,2007,(3):31-39.

[17] 曾庆飞,孔繁翔,毛志刚等. 稳定性氮同位素技术研究太湖梅梁湾区域营养盐差异. 农业环境科学学报, 2012,31 (4) :813-818.

[18］王伟伟. 长江口潮滩营养动态与稳定同位素指示研究 [学位论文].上海:华东师范大学, 2011:4.

[19] 梁 越. 鄱阳湖区蚌湖重金属及氮的生物地球化学与同位素示踪 [学位论文]. 南昌:南昌大学, 2014:6.

[20] 林 琳, 吴敬禄, 曾海鳌等. 人类活动对太湖水环境影响的稳定氮同位素示踪. 湖泊科学, 2012,24(4):546-552. DOI 10. 18307/2012.0407.

[21] 沈 吉,曹建廷. 岱海湖水盐度与氧同位素定量关系的建立. 第四纪研究, 2000,20(2):211.

[22] 汪敬忠, 吴敬禄, 曾海鳖等. 内蒙古河套平原水体同位素及水化学特征. 地球科学与环境学报, 2013,35 (4): 104-112.

[23] 曾海鳌,吴敬禄. 塔吉克斯坦水体同位素和水化学特征及成因. 水科学进展,2013,24(2):272-279.

[24] 张 玉,王洪滨,何 江等. 内蒙古达里诺尔湖水质现状调查. 水产科学,2008,27(12):671-673.

[25] 国家环境保护总局《水和废水监测分析方法》编委会. 水和废水监测分析方法: 第 4 版. 北京: 中国环境科学出版 
社,2002.

[26] MartinTL, Kaushik NK, Trevors JT et al. Review: denitrification in temperate climate riparian zones. Water, Air, and Soil Pollution,1999,111(1):171-186.

[27] Meyer A, Combroux I, Tremolieres M. Dynamics of nutrient contents (phosphorus, nitrogen) in water, sediment and plants after restoration of connectivity in side-channels of the river rhine. Restoration Ecology,2013,21(2):232-241.

[28] 马妮娜, 杨小平. 巴丹吉林沙漠及其东南边缘地区水化学和环境同位素特征及其水文学意义. 第四纪研究, 2008, 28 (4):702-711.

[29] 张 智, 刘亚丽, 龙腾锐. 重庆双龙湖水草对营养盐的吸附与释放试验研究. 资源环境与工程, 2005, 19 (4): 305-310.

[30] Fellman JB, D'Amore DV, Hood E. An evaluation of freezing as a preservation technique for analyzing dissolved organic C, N and P in surface water samples. Science of the Total Environment, 2008, 392(2/3):305-312.

[31] 宋玫峰,刘道平,邬志敏. 雪晶成核和生长机理研究. 制冷学报, 2004, (3) :46-50.

[32] Gao W, Smith DW, Sego DC. Ice nucleation in industrial wastewater. Cold Regions Science and Technology,1999,29(2): $121-133$.

[33] William RC. Thermodynamics and microphysics of clouds. Fort Collins: Colorado State University, 2000:21-30.

[34] 姜远光. 溴氨酸废水太阳光催化降解与冷冻处理技术研究 [学位论文]. 天津:天津大学, 2009:67-69.

[35] 张 岩, 李畅游, 张 生等. 呼伦湖冰封期污染特征分析及对水处理的意义. 生态环境学报, 2011, 20 (8/9): 1289-1294.

[36] 张 生, 李畅游, 梁喜珍等. 基于模糊综合评价法的内蒙古达里诺尔湖水环境质量评价. 中国工程科学,2010,12 (6) $: 28-31$.

[37] Shen HT. Research on river ice processes: Progress and missing links. Journal of Cold Regions Engineering, 2003,17 (4) : $135-142$.

[38] Jonsson CE, Leng MJ, Rosqvist GC et al. Stable oxygen and hydrogen isotopes in sub-Arctic lake waters from northern Sweden. Journal of Hydrology,2009,376 (1/2):143-151.

[39] 张 岩.乌梁素海结冰过程中污染物迁移机理及其应用研究 [学位论文]. 呼和浩特: 内蒙古农业大学,2012:4.

[40] 曾海鳌, 吴敬禄, 刘 文等. 哈萨克斯坦东部水体氢、氧同位素和水化学特征. 干旱区地理,2013,36(4):662-668. 